Original Research Paper

\title{
Knowledge, Training Status and Willingness to Implement Cardiopulmonary Resuscitation of Medical University Students in Chongqing, China
}

\author{
${ }^{1}$ Huixian Zhou, ${ }^{1}$ Chuan Pu, ${ }^{2}$ Feng Chen, ${ }^{3}$ Dianguo Xing, ${ }^{1}$ Jiani Mao, ${ }^{1}$ Ling Jia and ${ }^{1 *}$ Yan Zhang \\ ${ }^{1}$ Department of Epidemiology and Health Statistics, School of Public Health and Management, \\ Research Centre for Medicine and Social Development, Innovation Centre for Social Risk Governance in Health, \\ Chongqing Medical University, No.1, Medical College Road, Yuzhong District, Chongqing 400016, China \\ ${ }^{2}$ Department of Pre-Hospital Emergency, Chongqing Emergency Medical Centre, \\ Chongqing University Central Hospital, No.1 Jiankang Road, Yuzhong District, Chongqing 400016, China \\ ${ }^{3}$ Office of Health Emergency, Chongqing Municipal Health Commission, No.6, \\ Qilong Road, Yubei District, Chongqing 401147, China
}

\author{
Article history \\ Received: 02-01-2021 \\ Revised: 22-03-2021 \\ Accepted: 25-03-2021 \\ Corresponding Author: \\ Yan Zhang \\ Department of Epidemiology \\ and Health Statistics, School of \\ Public Health and \\ Management, Research Centre \\ for Medicine and Social \\ Development, Innovation \\ Centre for Social Risk \\ Governance in Health, \\ Chongqing Medical University, \\ No.1, Medical College Road, \\ Yuzhong District, Chongqing \\ 400016, China \\ Email: zhangyan@cqmu.edu.cn
}

\begin{abstract}
Timely bystander Cardiopulmonary Resuscitation (CPR) is key to improving survival from out-of-hospital cardiac arrest. Medical university students are potential bystander CPR providers. This study aimed to identify the current level of CPR knowledge, the present status of training and factors affecting the willingness to perform CPR among medical university students in Chongqing, China. Random sampling method was used and a total of 1159 medical university students were included in this study. A self-administered structured questionnaire was used, which included: Demographic characteristics, basic CPR knowledge, CPR training experience, variables of the Theory of Planned Behavior and willingness to implement CPR. The data were analyzed using $x^{2}$ test and multivariate logistic regression analysis. The respondents' mean CPR knowledge score was $3.19 \pm 1.81$ (total of 6 points). Forty-eight point one percent of the respondents had received CPR training and $85.2 \%$ said they were willing to participate in CPR training. In case of cardiac arrest, $49.9 \%$ of respondents were willing to perform CPR. It was found that respondents with CPR training experience, high CPR knowledge level, high Subjective Norm (SN) scores, high Attitude towards the Behavior (AB) scores and high Perceived Behavioral Control (PBC) scores were more willing to perform CPR. It is necessary to incorporate CPR courses into medical universities' compulsory curriculum to increase the willingness to implement CPR.
\end{abstract}

Keywords: Cardiopulmonary Resuscitation, Medical University Students, The Theory of Planned Behavior, Training, Willingness

\section{Introduction}

Out-of-Hospital Cardiac Arrest (OHCA) is a leading cause of mortality worldwide and is defined as the loss of functional cardiac mechanical activity and systemic circulation outside of a hospital (Myat et al., 2018). More than 20,000 people die each year from OHCA in Canada (Vaillancourt et al., 2013), 350,000 in the United States (Hansen et al., 2015) and 544,000 in China (Chen et al., 2017). Survival rates for OHCA are generally low worldwide, at around $7.9 \%$ in the United Kingdom (Hawkes et al., 2017), 25\% in Norway (Lindner et al., 2011) and less than 1\% in
China (Zhao et al., 2013). The best time to resuscitate a cardiac arrest patient is within 4 min (Zhao et al., 2013); however, it takes 5-8 min for the Emergency Medical Services (EMS) to arrive (Birkun and Kosova, 2018). Therefore, bystander Cardiopulmonary Resuscitation (CPR) before EMS arrival is critical for OHCA patients. A study in the United States (Fordyce et al., 2017) found that OHCA patients who received bystander CPR in a public place had a significantly improved survival rate than those who did not, with an OR-value of 4.33.

Although bystander CPR effectively improves patient survival and quality of prognosis, the implementation rate is low. The global bystander CPR rate is 
approximately 32\% (Sasson et al., 2010) and the average bystander CPR rate in 8 large and medium-sized cities in China is only $4.5 \%$ (Xu et al., 2017), which is related to the low CPR training rate in China. Bystander CPR training in China started late and CPR training has not yet been incorporated into primary, secondary and higher education curricula (Hu et al., 2019) and even medical universities have not made it a compulsory course for all students (Sun et al., 2020); the prevalence of CPR training is less than 1\% (Wang et al., 2018), which is not commensurate with China's economic and social development. In 2019, the Chinese government launched the Health China Initiative (2019-2030) to encourage mass emergency rescue training and increase the proportion of people with training certificates to $1 \%$ and above and $3 \%$ and above by 2022 and 2030, respectively (Health China Initiative Promotion Committee, 2019). With their medical knowledge and medical literacy, medical university students are potentially a significant group of people who are highly likely to implement bystander CPR and spread CPR knowledge and skills and should be a priority training group in the public emergency ambulance training strategy.

However, having the knowledge and skills to perform CPR is not a sufficient condition to perform CPR. The Theory of Planned Behavior (TPB) believes that behavioral intention is the most direct factor that affects behavior and the best predictor of behavior. The 2010 American Heart Association guidelines (Field et al., 2010) for cardiopulmonary resuscitation and emergency cardiovascular care were the first to place equal importance on improving bystander willingness to implement CPR and skill acquisition. Zhou et al. (2019) showed that even among Chinese medical personnel with some first aid skills, only $73.9 \%$ were willing to implement bystander CPR for strangers. The study results by Yaghmour and Movahed (2015) showed that only $40 \%$ of Iranian nurses were willing to implement bystander CPR that required artificial respiration. Studies have been conducted to analyze the factors that influence willingness to implement in terms of personal characteristics (Son et al., 2017), level of CPR knowledge (Birkun and Kosova, 2018) and CPR training experience (Dobbie et al., 2018). In addition to the above factors, according to the Theory of Planned Behavior (TPB), behavioral intentions are also influenced by Subjective Norm (SN), Attitude towards the Behavior (AB) and Perceived Behavioral Control (PBC) (Ajzen, 1991). The influence of significant others and prevailing social values on actors' implementation of CPR and the positive or negative attitudes actors hold towards implementing CPR may influence the willingness to implement CPR. TPB theory has been widely used to analyze health behaviors and behavioral intentions (Mentrikoski et al., 2019; Shimazaki et al., 2017; Boudreau and Godin, 2007). Therefore, we introduce TPB variables into the overall framework of the analysis of factors influencing willingness to administer CPR to understand better the deeper psychological, motivational factors that prompt bystander CPR implementation.

While medical university students are potentially a significant group of people who are highly likely to perform bystander CPR, there is a relative lack of data on the level of CPR knowledge, the present status of training and willingness to perform CPR among medical university students in China, especially in the relatively economically disadvantaged western region of China. Therefore, this study was conducted to understand the level of CPR knowledge, the present status of training and implementation willingness of medical university students in Chongqing and the factors influencing the willingness to implement. The variables of TPB were introduced into the analysis of factors influencing willingness to implement CPR in order to identify the psychological motivations that may influence willingness to act and to develop theory-based interventions.

\section{Methods}

\section{Survey Setting and Data Collection}

This study was conducted in Chongqing, in western China. Chongqing is one of the four municipalities directly under the Chinese central government's jurisdiction, with an area of $82,400 \mathrm{~km}^{2}$ and a population of 31.24 million and is known for its mountainous city. There are two physicians per 1,000 population and 3.1 nurses per 1,000 population, which are lack health resources. The governmentsponsored 120 system provides Chongqing EMS. Due to the uneven distribution of emergency medical stations, traffic congestion and topography, it takes 20 min for EMS to reach the wealthiest urban areas and even longer in rural areas.

Chongqing Medical University is the only medical university in Chongqing that has been certified by the Chinese Ministry of Education to specialize in clinical medicine. It enrolls students from 31 provinces, autonomous regions and municipalities nationwide enroll students, of which $82.6 \%$ are from western China, with 25,367 full-time students, including clinical medicine, nursing, basic medicine, preventive medicine, pharmacy, medical laboratory, medical English, health service management and other medical-related majors.

Random sampling was carried out in students' dormitories. All dormitory buildings are selected and one dormitory is randomly selected from each floor. All students in the dormitory scan the QR code and fill in the electronic questionnaire. As of October 15, 2019, a total of 1210 questionnaires were collected. Fifty-one questionnaires were excluded due to incomplete and contradictory answers, yielding 1159 valid questionnaires with a $95.8 \%$ validity rate. 


\section{Measurement}

A five-part self-administered questionnaire was used for this survey:

Part 1 included general demographic characteristics: gender, grade and major.

Part 2 was CPR basic knowledge, including 6 questions with only one correct answer per question and correct answers counted for 1 point. Higher scores indicated a higher level of knowledge. Cronbach's alpha coefficient was 0.711 .

Part 3 consisted of content related to CPR training, including training experience, willingness to participate and barriers to CPR training participation.

Part 4 measured TPB variables and included six questions on three dimensions: $\mathrm{SN}, \mathrm{AB}$ and $\mathrm{PBC}$. A 5-point Likert scale was used, with 1 indicating "strongly disagree/strongly unconfident/very few" and 5 indicating "strongly agree/strongly confident/majority", assigning a score of 1 to 5 . Cronbach 's alpha coefficient was 0.704 .

Part 5 is composed of CPR implementation's relevant content, including willingness to provide awareness check, respiratory examination and call 120, willingness to perform CPR and barriers to performing CPR.

\section{Data Analysis}

All statistical analyses were computed using Statistical Package for the Social Sciences Version 26.0. (SPSS, Inc., Chicago, IL, USA). Continuous variables were expressed as means and standard deviations and categorical variables expressed as counts and composition ratios. The CPR knowledge score was calculated with a total score of 6 out of 6 questions, with scores of 0 to 3 considered low and 4 to 6 considered high. $\chi^{2}$ test was used to compare differences in CPR training rates and differences in CPR knowledge level among students in different majors and grades and differences in barriers to CPR training participation and differences in barriers to CPR implementation among respondents who had and had not received CPR training. Multivariate logistic regression was used to explore factors influencing willingness to attend CPR training and willingness to perform CPR. All control variables were entered using the enter method. The level of $p<0.05$ was considered statistically significant in all tests.

\section{Results}

\section{General Demographic Characteristics}

Among the respondents, 451 (38.9\%) were males, $708(61.1 \%)$ were females. $448(38.7 \%)$ were in the lower grades of undergraduate, $414(35.7 \%)$ were in the upper grades of undergraduate and 297 (25.6\%) had a master's degree or above. There were $456(39.3 \%)$ students in clinical and nursing majors and 703 (60.7\%) in other medical-related majors.

\section{CPR Training Status}

Of the respondents, $558(48.1 \%)$ had received CPR training. $29.2 \%$ in the lower undergraduate years had received $C P R$ training, with no difference between majors $(\mathrm{p}=0.744)$. Clinical and nursing training rates were significantly higher $(\mathrm{p}<0.001)$ in the upper grades of undergraduate majors, 57.5 percentage points higher than in their lower grades, while other medical-related majors were only 3.8 percentage points higher than in their lower grades. This gap has narrowed among respondents with a master's degree and above (Fig. 1).

An overwhelming majority $(85.2 \%)$ of the respondents indicated their willingness to attend $\mathrm{CPR}$ training. Females (OR: 2.182; 95\% CI: 1.555-3.063, $\mathrm{p}<0.001)$ and those with high CPR knowledge level (OR: 2.123; 95\% CI: 1.370-3.292, p<0.001) were more willing to participate in CPR training. Barriers to attending or continuing CPR training included fear of a disconnect between theory and practice during training $(52.5 \%)$, few opportunities for application $(51.8 \%)$ and forgetfulness after learning (49.0\%). Compared to respondents who had not received CPR training, more of those who had received CPR training cited few application opportunities and forgetfulness after learning as barriers to attending CPR training. Whereas $63.1 \%$ and $34.8 \%$ of respondents who had not received CPR training, respectively, cited difficulty accessing learning pathways and lack of time as barriers to attending CPR training, much higher than those who had attended the training (Table 1).

\section{CPR Knowledge}

The respondents' mean CPR knowledge score was $3.19 \pm 1.81$, with an entirely correct knowledge rate (score of 6) of $13.4 \%$ and a high knowledge level rate (score of 4 and above) of $42.2 \%$. The lowest accuracy rates were $41.0 \%$ and $44.1 \%$ for respiratory arrest judgment and the frequency and depth of CPR compressions, respectively (Table 2). The rate of CPR high knowledge level (scores of 4 and above) was less than $30 \%$ for all medical university students in the lower grades, with clinical and nursing majors slightly higher than students in other majors $(\mathrm{p}=0.032)$. The high knowledge level was 62.2 percentage points higher for clinical and nursing majors in the upper grades of undergraduate compared to the lower grades, but only 12.2 percentage points higher for other medical-related majors compared to the lower grades (Fig. 2).

\section{Measurement Results of Variables of TPB}

Table 3 shows the results of each item in TPB. The mean score for $\mathrm{AB}$ was highest at $4.06 \pm 0.78$ and the 
mean score for $\mathrm{PBC}$ was the lowest at $2.69 \pm 0.89$. In PBC, only $15.0 \%$ of the respondents felt confident about implementing CPR (score of 4 or 5) and even among those who had received training in CPR, only $19.7 \%$ of the students surveyed felt confident about implementing CPR.

\section{Willingness and Barriers to Perform CPR}

In cardiac arrest, $49.9 \%$ of respondents were willing to perform CPR and $81.7 \%$ said they would be willing to provide awareness check, respiratory examination and call 120. Respondents with CPR training experience, high CPR knowledge level, high SN scores, high AB scores and high $\mathrm{PBC}$ scores were more likely to perform CPR. In addition to the non-significant PBC variables, these factors were also predictors of the willingness to provide awareness check, respiratory examination and call 120 (Table 4).

The main reasons for reluctance to perform CPR included: lack of confidence in one's ability to provide first aid $(67.1 \%)$, fear of secondary harm to the injured person $(58.4 \%)$ and fear of causing legal disputes (46.7\%). Respondents with no CPR training were not confident in their ability to provide first aid $(74.5 \%)$ and feared secondary harm to the injured $(62.6 \%)$, while respondents with CPR training were more afraid of causing legal trouble $(50.2 \%)$ and catching a disease $(21.5 \%)$ (Table 5).

Table 1: Barriers to participation in CPR training

\begin{tabular}{|c|c|c|c|c|}
\hline Barrier & $\begin{array}{l}\text { Total, } \\
\text { n }(\%)\end{array}$ & $\begin{array}{l}\text { Untrained, } \\
\mathrm{n}(\%)\end{array}$ & $\begin{array}{l}\text { Trained, } \\
\mathrm{n}(\%)\end{array}$ & $P$-value \\
\hline $\begin{array}{l}\text { Fear of a disconnect between theory } \\
\text { and practice during training }\end{array}$ & $609(52.5)$ & $316(52.6)$ & $293(52.5)$ & 0.981 \\
\hline Few opportunities for application & $600(51.8)$ & $275(45.8)$ & $325(58.2)$ & 0.000 \\
\hline Forgetfulness after learning & $568(49.0)$ & $272(45.3)$ & $296(53.0)$ & 0.008 \\
\hline Difficult access to learning pathways & $564(48.7)$ & $379(63.1)$ & $185(33.2)$ & 0.000 \\
\hline No time & $333(28.7)$ & $209(34.8)$ & $124(22.2)$ & 0.000 \\
\hline Lack of clarity on the importance of mastery & $146(12.6)$ & $78(13.0)$ & $68(12.2)$ & 0.685 \\
\hline Not interested & $79(6.8)$ & $45(7.5)$ & $34(6.1)$ & 0.347 \\
\hline Other & $31(2.7)$ & $9(1.5)$ & $22(3.9)$ & 0.010 \\
\hline
\end{tabular}

CPR, cardiopulmonary resuscitation

Table 2: Correct rate of CPR knowledge

\begin{tabular}{lll}
\hline CPR knowledge & Total(n) & Percentage $(\%)$ \\
\hline 1. How to determine respiratory arrest & 475 & 41.0 \\
2. How to determine cardiac arrest & 789 & 68.1 \\
3. Ways of judging unconsciousness & 586 & 50.6 \\
4. Position of CPR compressions & 770 & 66.4 \\
5. Frequency and depth of CPR compressions & 511 & 44.1 \\
6. The correct sequence of CPR operations & 562 & 48.5 \\
\hline
\end{tabular}

$\mathrm{CPR}$, cardiopulmonary resuscitation

Table 3: Items and score of TPB scale

\begin{tabular}{|c|c|c|c|}
\hline Variable & Item & Title & $\bar{x} \pm s$ \\
\hline \multirow[t]{3}{*}{$\mathrm{SN}$} & sn1 & $\begin{array}{l}\text { Do you think your close family/ friends approve } \\
\text { of you implementing CPR on strangers? }\end{array}$ & $3.75 \pm 0.93$ \\
\hline & $\operatorname{sn} 2$ & $\begin{array}{l}\text { How many people do you think would } \\
\text { implement CPR on strangers? }\end{array}$ & $3.04 \pm 1.02$ \\
\hline & $\operatorname{sn} 3$ & $\begin{array}{l}\text { In an emergency situation, bystanders } \\
\text { should offer what help they can. }\end{array}$ & $4.11 \pm 0.83$ \\
\hline \multirow[t]{2}{*}{$\mathrm{AB}$} & $a b 1$ & $\begin{array}{l}\text { I would regret or be upset if someone } \\
\text { else was disabled or killed because I failed } \\
\text { to implement CPR in a timely manner. }\end{array}$ & $3.95 \pm 0.98$ \\
\hline & $a b 2$ & $\begin{array}{l}\mathrm{CPR} \text { is valuable and I would have a great sense } \\
\text { of social value in implementing CPR to save others. }\end{array}$ & $4.17 \pm 0.83$ \\
\hline PBC & pbc1 & How confident are you that others are implementing CPR? & $2.69 \pm 0.89$ \\
\hline
\end{tabular}

TPB: The Theory of Planned Behavior; CPR, Cardiopulmonary Resuscitation; SN, Subjective Norm; AB, Attitude towards the Behavior; PBC, Perceived Behavioral Control 
Table 4: Analysis of willingness to perform CPR

\begin{tabular}{llll}
\hline Variables & $\begin{array}{l}\text { Willing to perform, } \\
\mathrm{n}(\%) / \bar{x} \pm s\end{array}$ & OR(95\%CI) & $P$-value \\
\hline Gender & $342(48.3)$ & 1.00 \\
Female & $236(52.3)$ & $1.254(0.944-1.665)$ & 0.118 \\
Male & & & 1.00 \\
Education & $184(41.1)$ & $1.374(0.994-1.899)$ & 0.054 \\
Lower grades of undergraduate & $229(55.3)$ & $1.321(0.916-1.904)$ & 0.136 \\
Upper grades of undergraduate & $165(55.6)$ & & 0.788 \\
Master's degree and above & & 1.00 & \\
Major & $309(44.0)$ & $1.043(0.769-1.414)$ & \\
Other medical-related majors & $269(59.0)$ & 1.00 & $1.607(1.185-2.178)$ \\
Clinical and nursing majors & & & 0.002 \\
Have you attended CPR training & $236(39.3)$ & 1.00 & 0.013 \\
No & $342(61.3)$ & $1.513(1.090-2.100)$ & 0.000 \\
Yes & & $2.235(1.757-2.843)$ & 0.000 \\
CPR knowledge & $278(41.5)$ & $1.703(1.384-2.096)$ \\
Low level & $300(61.3)$ & $1.883(1.588-2.234)$ & 0.000 \\
High level & $3.88 \pm 0.64$ &
\end{tabular}

CPR, Cardiopulmonary Resuscitation

Table 5: Barriers to CPR implementation

\begin{tabular}{lllll}
\hline Barrier & Total, $\mathrm{n}(\%)$ & Untrained, $\mathrm{n}(\%)$ & Trained, $\mathrm{n}(\%)$ & $P$-value \\
\hline Lack of confidence in your first aid abilities & $778(67.1)$ & $448(74.5)$ & $330(59.1)$ & 0.000 \\
Fear of secondary harm to the injured & $677(58.4)$ & $376(62.6)$ & $301(53.9)$ & 0.003 \\
Fear of legal disputes & $541(46.7)$ & $261(43.4)$ & $280(50.2)$ & 0.021 \\
Fear of catching the disease & $209(18.0)$ & $89(14.8)$ & $120(21.5)$ & 0.003 \\
Fear of public opinion & $204(17.6)$ & $115(19.1)$ & $89(15.9)$ & 0.155 \\
Worried about being in danger during the treatment & $149(12.9)$ & $68(11.3)$ & $81(14.5)$ & 0.104 \\
Fear of seeing injury or illness & $87(7.5)$ & $41(6.8)$ & $46(8.2)$ & 0.359 \\
Other & $22(1.9)$ & $11(1.8)$ & $11(2.0)$ & 0.860 \\
\hline
\end{tabular}

CPR, Cardiopulmonary Resuscitation

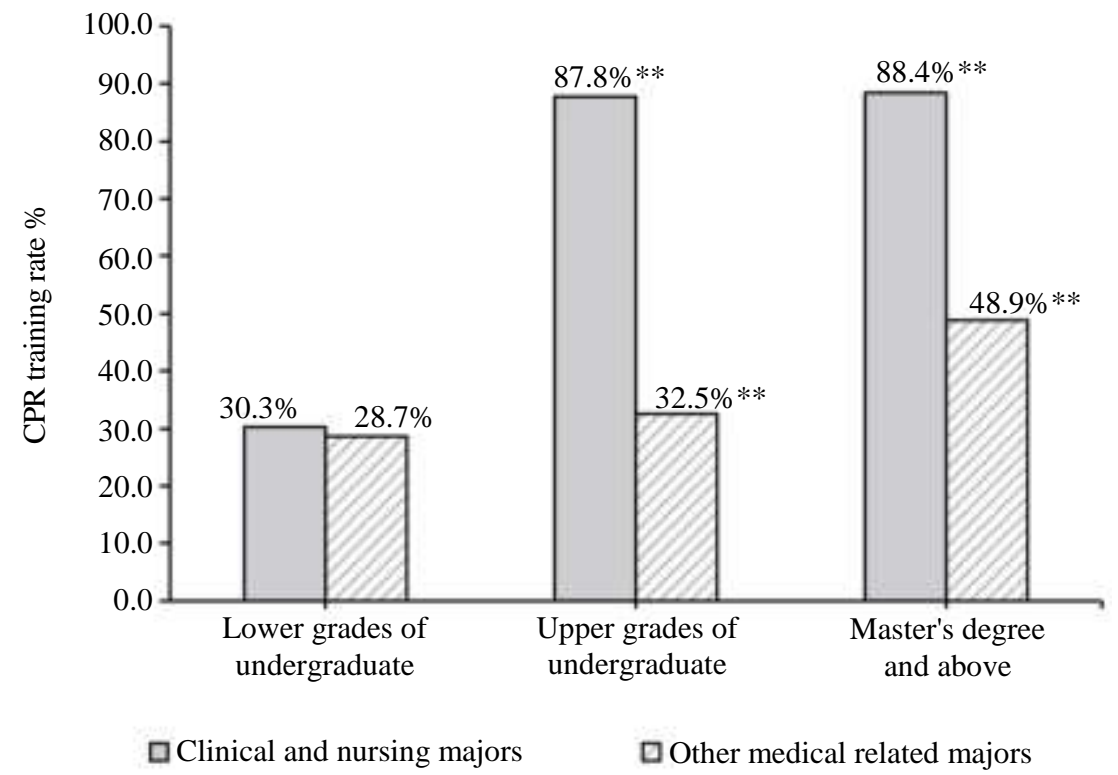

Fig. 1: Training rate of $\mathrm{CPR}$ across majors and grades. ** means $\mathrm{P}<0.001$; $\mathrm{CPR}$, cardiopulmonary resuscitation 


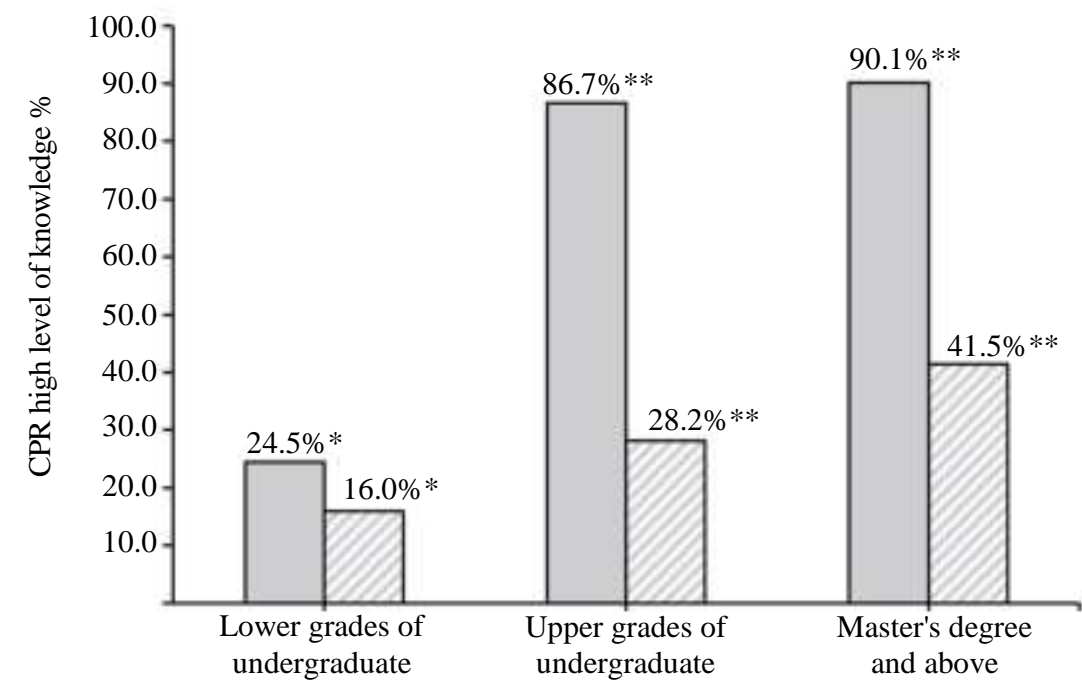

Clinical and nursing majors

$\square$ Other medical related majors

Fig. 2: CPR knowledge level of CPR across majors and grades. *means $\mathrm{P}<0.05$, **means $\mathrm{P}<0.001$; CPR, cardiopulmonary resuscitation

\section{Discussion}

In our research, the respondents' CPR knowledge's mean score was 3.19 \pm 1.81 (total score of 6) and less than $50 \%$ scored high (greater than or equal to 4). It was indicating that the respondents' knowledge of CPR was inadequate. Similar knowledge deficiencies were found among medical students in other developing countries, Jordan (Oteir et al., 2019), India (Aroor et al., 2014), Egypt (Mohammed et al., 2020). Lack of continuous and formal training may be the main reason for the lack of CPR knowledge among medical students in developing countries. Our findings show that the average CPR knowledge score for those who had not attended the training was only 2.33, significantly lower than those who had attended the training (4.10). However, only $48.1 \%$ of those surveyed had attended training, far below the general public's training rates in developed countries such as the United States (Anderson et al., 2014) and Norway (Bakke et al., 2016). Only 29.2\% of respondents in the lower undergraduate grades had participated in the training and the training rate for non-clinical and nursing students in the upper undergraduate grades was only 3.8 percentage points higher than in the lower grades. This suggests a lack of training opportunities for non-clinical and nursing students at the university level, even in medical universities and that the training they receive is more likely to come from the school or community activities near their home they attended in secondary school (Pan and Zhang, 2017). The lack of training opportunities is also illustrated by the fact that $63.1 \%$ of respondents with no training experience reported that difficulty accessing learning pathways was the most significant barrier to their CPR training participation. Despite this, over $85 \%$ of respondents expressed their desire to attend training.

The results of this survey show that $49.9 \%$ of the respondents were willing to perform CPR, which is similar to the findings of another Chinese municipality, Tianjin (45.3\%) (Lu et al., 2016) and Malaysia (51.4\%) (Chew and Yazid, 2008) for medical students, but lower than the findings of Italy (75\%) (Contri et al., 2017). Training experience and level of knowledge are important influences on willingness to implement CPR. The analysis showed that those with training and high knowledge were 1.607 and 1.513 times more willing to implement CPR than those with no training and insufficient knowledge, respectively, similar to the study of Son et al. (2017) and Dobbie et al. (2018).

Also, TPB variables, including $\mathrm{AB}, \mathrm{SN}$ and $\mathrm{PBC}$, positively affected respondents' willingness to implement CPR. AB scored the highest of the three variables, at $4.06 \pm 0.78$, indicating that medical university students generally recognize the value of implementing CPR and have a high sense of social responsibility. PBC scores were the lowest, with a mean score of only 2.69 . Respondents generally lacked confidence in implementing CPR, with $67.1 \%$ citing lack of confidence as a barrier to implementing CPR. On the one hand, it is related to the lack of training and the low level of CPR knowledge of the respondents. On the other hand, it may be related to the poor practicality of the training courses (Huang et al., 2020), the lack of retraining (Yang et al., 2019) and the lack of confidenceboosting training content (Huang et al., 2016). The survey results also showed that $59.1 \%$ of those who had 
taken part in the training were not confident in their first aid skills and more than half of them expressed concern about the disconnect between theory and practice during the training and forgetfulness after learning. The positive effect of SN on medical university students' willingness to give help was most significant. The item "In an emergency situation, bystanders should offer what help they can" scored the highest, which is in line with the traditional Chinese virtue of being brave and willing to help others (Xue, 2017), as well as the core spirit of the Hippocratic Oath of medical students to save lives and help the sick for the benefit of patients. The other two items scored relatively low, with medical university students believing that those around them may not be very supportive of performing CPR for strangers and that relatively few people perform CPR in reality. This may be related to their perceived barriers to implementing CPR. In addition to the lack of confidence in first aid capabilities, fear of legal disputes was the most critical barrier factor to implementing CPR as perceived by the respondents. The survey results show that $46.7 \%$ of respondents are concerned about legal disputes arising from the implementation of bystander CPR, unlike the findings in Denmark (Malta Hansen et al., 2017) and Scotland (Dobbie et al., 2018) (8\%). In China, it was not until 2017 that the "good man law" provisions were written into the General Principles of the Civil Law. The late introduction of the relevant exemption provisions leads to its insufficient social influence up until now. and it is still the provisions' principle which means there are no comprehensive and systematic details of the provisions of the exemptions for strangers to perform first aid. Thus the feasibility is relatively not high.Besides, during the legal gap, the case of "saving a person from being blackmailed" (Fu, 2012) was misinterpreted and overly fermented in the online media, which brought negative social impact and increased people's concern about possible legal disputes. Based on this, medical university students may tend to believe that although they should help in terms of mainstream values, loved ones and friends may be less supportive of implementing CPR for their protection and fear of getting into trouble and relatively few people in reality implement CPR.

More respondents $(81.7 \%)$ were willing to provide consciousness and respiratory checks and call emergency services for patients than to perform CPR, which maybe related to the respondents' perception that the above measures are simpler and generally have a higher level of self-confidence. This suggests to us that the vast majority of medical university students are willing to lend a helping hand when faced with a patient in potential cardiac arrest, but may be afraid to perform CPR given their lack of training and confidence, fear of secondary harm to the patient and legal disputes.
In summary, we recommend that the government develop training plans to incorporate CPR training and retraining into primary, secondary and higher education curricula in a planned manner. In particular, it should be made a mandatory course for all students in medical universities. Relevant institutions and researchers should develop online and offline training courses according to the population's characteristics and focus on adding confidenceboosting training content to the training curriculum; standardize the assessment process and standards and issue qualification certificates with certain validity for those who pass the exam. The legislature should expedite the introduction of more detailed and operational legal provisions for public first aid exemptions to protect rescuers' rights and interests. Emergency medical rescue dispatch agencies can instruct bystanders on the implementation of CPR via APP video or telephone to enhance rescuers' confidence.

\section{Limitation}

Our study has several limitations. First, this study was a cross-sectional investigation and it was not possible to determine the exact causal relationship between the variables. Second, this study was only conducted on medical university students in Chongqing, which has a particular regional dimension and may limit the study findings' generalization. Third, the respondents' willingness to perform CPR does not mean that they would perform CPR in a real situation and future studies should focus on the actual behavior of performing CPR. Finally, this study used the Theory of Planned Behavior as a framework to identify some of the influences on bystanders' willingness to implement CPR and future research could also focus on actual powerful analytical framework models, such as the Integrated Behavior Model (IBM), to more fully explore the influences on implementing CPR.

\section{Conclusion}

The level of CPR knowledge of Chongqing medical university students was poor and they had a positive attitude towards CPR training, but the percentage of those who had received CPR training was not high. About half of the students surveyed were willing to implement bystander $\mathrm{CPR}$ and $\mathrm{AB}, \mathrm{SN}$ and $\mathrm{PBC}$ positively impacted. Lack of confidence in one's ability and fear of legal disputes are the most significant barriers to implementing bystander CPR. Intensive training and improved legislation are recommended to increase willingness to implement CPR.

\section{Acknowledgment}

The authors would like to express their gratitude to every participant in this survey. 


\section{Funding Information}

This study was funded by Chongqing Federation of Social Science Circles (2019YBGL057) and Medical Research Project of Chongqing Science and Technology Commission united with Chongqing Municipal Health Commission (2019ZLXM002).

\section{Authors Contributions}

Yan Zhang: Conceptualization, Methodology, Writing-Reviewing and Editing, Project Administration.

Huixian Zhou: Methodology, Investigation, Data analysis, Writing-Original Draft.

Chuan Pu, Feng Chen and Dianguo Xing: Methodology, Supervision, Feedback.

Jiani Mao and Ling Jia: Investigation, Data Curation, Feedback.

\section{Ethics Approval}

This study was approved by the Ethics Committee of Chongqing Medical University (Date Approved: October 8, 2019).

\section{References}

Ajzen, I. (1991). The theory of planned behavior. Organizational Behavior and Human Decision Processes, 50(2), 179-211. https://www.sciencedirect.com/science/article/abs/pi i/074959789190020T

Anderson, M. L., Cox, M., Al-Khatib, S. M., Nichol, G., Thomas, K. L., Chan, P. S.,... \& Peterson, E. D. (2014). Rates of cardiopulmonary resuscitation training in the United States. JAMA Internal Medicine, 174(2), 194-201. https://jamanetwork.com/journals/jamainternalme dicine/article-abstract/1779728

Aroor, A. R., Saya, R. P., Attar, N. R., Saya, G. K., \& Ravinanthanan, M. (2014). Awareness about basic life support and emergency medical services and its associated factors among students in a tertiary care hospital in South India. Journal of Emergencies, Trauma and Shock, 7(3), 166. https://www.ncbi.nlm.nih.gov/pmc/articles/PMC4 $126115 /$

Bakke, H. K., Steinvik, T., Angell, J., \& Wisborg, T. (2016). A nationwide survey of first aid training and encounters in Norway. BMC Emergency Medicine, $17(1)$ $1-7$. https://bmcemergmed.biomedcentral.com/articles/10 .1186/s12873-017-0116-7
Birkun, A., \& Kosova, Y. (2018). Social attitude and willingness to attend cardiopulmonary resuscitation training and perform resuscitation in the Crimea. World Journal of Emergency Medicine, 9(4), 237. https://www.ncbi.nlm.nih.gov/pmc/articles/PMC6 $117537 /$

Boudreau, F., \& Godin, G. (2007). Using the Theory of Planned Behaviour to predict exercise intention in obese adults. Canadian Journal of Nursing Research Archive, 39(2), 112-125. https://cjnr.archive.mcgill.ca/article/view/2056

Chen, M., Wang, Y., Li, X., Hou, L., Wang, Y., Liu, J., \& Han, F. (2017). Public knowledge and attitudes towards bystander cardiopulmonary resuscitation in China. BioMed Research International, 2017, 3250485 .

https://www.hindawi.com/journals/bmri/2017/325 0485/

Chew, K. S., \& Yazid, M. N. A. (2008). The willingness of final year medical and dental students to perform bystander cardiopulmonary resuscitation in an Asian community. International Journal of Emergency Medicine, 1(4), 301-309. https://link.springer.com/article/10.1007\%252Fs122 45-008-0070-y

Contri, E., Bonomo, M. C., Costantini, G., Manera, M., Bormetti, M., Tonani, M., \& Baldi, E. (2017). Are final year medical students ready to save lives in Italy? Not yet. Emergency Medicine Journal, 34(8), 556-556. https://emj.bmj.com/content/34/8/556

Dobbie, F., MacKintosh, A. M., Clegg, G., Stirzaker, R., \& Bauld, L. (2018). Attitudes towards bystander cardiopulmonary resuscitation: Results from a crosssectional general population survey. PloS One, 13(3), e0193391. https://journals.plos.org/plosone/article?id=10.1371/ journal.pone.0193391

Field, J. M., Hazinski, M. F., Sayre, M. R., Chameides, L., Schexnayder, S. M., Hemphill, R.,... \& Vanden Hoek, T. L. (2010). Part 1: executive summary: 2010 American Heart Association guidelines for cardiopulmonary resuscitation and emergency cardiovascular care. Circulation, 122(18_suppl_3), S640-S656.

https://www.ahajournals.org/doi/full/10.1161/CIRC ULATIONAHA.110.970889

Fordyce, C. B., Hansen, C. M., Kragholm, K., Dupre, M. E., Jollis, J. G., Roettig, M. L.,... \& Granger, C. B. (2017). Association of public health initiatives with outcomes for out-of-hospital cardiac arrest at home and in public locations. JAMA Cardiology, 2(11), 1226-1235.

https://jamanetwork.com/journals/jamacardiology/ar ticle-abstract/2656353 
Fu, Y. (2012). When Faith Crisis Encounters Harmonious Judicature-A Perspective on the Relationship between Judicature and Media from the Peng Yu Case. Journal of Law Application, 2012(12), 2-6. https://kns.cnki.net/kcms/detail/detail.aspx?FileN ame $=$ FLSY201212003 $\&$ DbName $=$ CJFQ2012

Hansen, C. M., Kragholm, K., Pearson, D. A., Tyson, C., Monk, L., Myers, B.,... \& Granger, C. B. (2015). Association of bystander and firstresponder intervention with survival after out-ofhospital cardiac arrest in North Carolina, 20102013. JAMA, 314(3), 255-264. https://jamanetwork.com/journals/jama/articleabstract $/ 2397833$

Hawkes, C., Booth, S., Ji, C., Brace-McDonnell, S. J., Whittington, A., Mapstone, J.,... \& Perkins, G. D. (2017). Epidemiology and outcomes from out-ofhospital cardiac arrests in England. Resuscitation, 110 , 133-140. https://www.sciencedirect.com/science/article/abs /pii/S0300957216305470

Health China Initiative Promotion Committee. (2019). Healthy China Initiative (2019-2030). http://www.gov.cn/xinwen/201907/15/content_5409694.htm.

Hu, R., Gao, H., \& Jiang, Z. (2019). The status quo and countermeasures of first aid training for primary and middle school students at home and abroad. China Health Industry, 16(09),190-192. https://kns.cnki.net/kcms/detail/detail.aspx?FileN ame $=$ WSCY201909090\&DbName $=$ CJFQ2019

Huang, Q., Hu, C., \& Mao, J. (2016). Are Chinese students willing to learn and perform bystander cardiopulmonary resuscitation?. The Journal of Emergency Medicine, 51(6), 712-720. https://www.sciencedirect.com/science/article/abs/pi i/S0736467916306886

Yang, K., Sang, W., Pan, C., Xu, F. \& Chen, Y. (2019). Current status and prospects of investigation of cardiac arrest and resuscitation. Chinese Journal of Practical Internal Medicine, 39(10), 842-846. https://kns.cnki.net/kcms/detail/detail.aspx?FileN ame $=$ SYNK201910002 \&DbName $=$ CJFQ2019

Lindner, T. W., Søreide, E., Nilsen, O. B., Torunn, M. W., \& Lossius, H. M. (2011). Good outcome in every fourth resuscitation attempt is achievablean Utstein template report from the Stavanger region. Resuscitation, 82(12), 1508-1513. https://www.sciencedirect.com/science/article/abs /pii/S030095721100390X
Lu, C., Jin, Y., Meng, F., Wang, Y., Shi, X., Ma, W.,... \& Xing, Q. (2016). An exploration of attitudes toward bystander cardiopulmonary resuscitation in university students in Tianjin, China: a survey. International Emergency Nursing, 24, 28-34. https://www.sciencedirect.com/science/article/abs/pi i/S1755599X1500052X

Malta Hansen, C., Rosenkranz, S. M., Folke, F., Zinckernagel, L., Tjørnhøj-Thomsen, T., Torp-Pedersen, C.,... \& Hulvej Rod, M. (2017). Lay bystanders' perspectives on what facilitates cardiopulmonary resuscitation and use of automated external defibrillators in real cardiac arrests. Journal of the American Heart Association, 6(3), e004572. https://www.ahajournals.org/doi/full/10.1161/JAHA. 116.004572

Mentrikoski, J. M., Duncan, C. L., Enlow, P. T., \& Aballay, A. M. (2019). Predicting Adolescents' Intentions to Engage in Fire Risk Behaviors: An Application of the Theory of Planned Behavior. Burns, 45(5), 1242-1250. https://www.sciencedirect.com/science/article/abs/pi i/S030541791830411X

Mohammed, Z., Arafa, A., Saleh, Y., Dardir, M., Taha, A., Shaban, H.,.. \& Hirshon, J. M. (2020). Knowledge of and attitudes towards cardiopulmonary resuscitation among junior doctors and medical students in Upper Egypt: crosssectional study. International Journal of Emergency Medicine, $13(1)$ 19. https://link.springer.com/content/pdf/10.1186/s1224 5-020-00277-x.pdf

Myat, A., Song, K. J., \& Rea, T. (2018). Out-of-hospital cardiac arrest: current concepts. The Lancet, 391(10124), 970-979. https://www.sciencedirect.com/science/article/abs/pi i/S0140673618304720

Oteir, A. O., Almhdawi, K. A., Kanaan, S. F., Alwidyan, M. T., \& Williams, B. (2019). Cardiopulmonary resuscitation level of knowledge among allied health university students in Jordan: a crosssectional study. BMJ open, 9(11), e031725. https://bmjopen.bmj.com/content/9/11/e031725.ab stract

Sasson, C., Rogers, M. A., Dahl, J., \& Kellermann, A. L. (2010). Predictors of survival from out-of-hospital cardiac arrest: a systematic review and metaanalysis. Circulation: Cardiovascular Quality and Outcomes, $3(1), \quad 63-81$. https://www.ahajournals.org/doi/full/10.1161/CIRC OUTCOMES.109.889576 
Shimazaki, T., Bao, H., Deli, G., Uechi, H., Lee, Y. H., Miura, K., \& Takenaka, K. (2017). Cross-cultural validity of the theory of planned behavior for predicting healthy food choice in secondary school students of Inner Mongolia. Diabetes \& Metabolic Syndrome: Clinical Research \& Reviews, $\quad 11, \quad$ S497-S501. https://www.sciencedirect.com/science/article/abs/pi i/S1871402117300668

Son, J. W., Ryoo, H. W., Moon, S., Kim, J. Y., Ahn, J. Y., Park, J. B.,... \& Kim, Y. J. (2017). Association between public cardiopulmonary resuscitation education and the willingness to perform bystander cardiopulmonary resuscitation: a metropolitan citywide survey. Clinical and Experimental Emergency Medicine, 4(2), 80-87. https://www.ncbi.nlm.nih.gov/pmc/articles/PMC5 511954/

Sun, X., Wang, Q., \& Zhang, M. (2020). Investigation and analysis of the status quo of first aid knowledge cognition among college students_-Taking $\mathrm{X}$ medical schools as an example. Assets and Finances in Administration and Institution, (14), 119-120. https://kns.cnki.net/kcms/detail/detail.aspx?FileName= XZSY202014057\&DbName=CJFQ2020

Vaillancourt, C., Kasaboski, A., Charette, M., Islam, R., Osmond, M., Wells, G. A.,... \& Grimshaw, J. M. (2013). Barriers and facilitators to CPR training and performing CPR in an older population most likely to witness cardiac arrest: a national survey. Resuscitation, $\quad$ 84(12), 1747-1752. https://www.sciencedirect.com/science/article/abs/pi i/S0300957213004012

Wang, L., Meng, Q., \& Yu, T. (2018). 2018 National consensus on cardiopulmonary resuscitation training in China. Zhonghua Wei Zhong Bing Ji Jiu Yi Xue, 30(5), 385-400.

https://europepmc.org/article/med/29764540

Huang, X., Liu, L., Xu, Z., Yang, C., Zhang, Q., Zheng, M. \& Huang, Z. (2020). Research on the public field first aid training system. Education Teaching Forum, (39), $137-138$ https://kns.cnki.net/kcms/detail/detail.aspx?FileNam e=JYJU202039063\&DbName=CJFQ2020

Xu, F., Zhang, Y., \& Chen, Y. (2017). Cardiopulmonary resuscitation training in China: current situation and future development. JAMA Cardiology, 2(5), 469-470. https://jamanetwork.com/journals/jamacardiology/ar ticle-abstract/2611938
Xue, M. (2017). Talking about the main ways of education for college students under the new situation (in Chinese). Western China Quality Education, 3(11), 96-97. https://kns.cnki.net/kcms/detail/detail.aspx?FileNam e=XBSJ201711067\&DbName=CJFQ2017

Yaghmour, N., \& Movahed, M. R. (2015). Willingness to perform chest compression only in witnessed cardiac arrest victims versus cardiopulmonary resuscitation in Iran. International Cardiovascular $\begin{array}{ll}\text { Research Journal, 7-9. } & \text { 9(1), }\end{array}$ https://www.sid.ir/en/journal/ViewPaper.aspx?ID=4 36464

Pan, Y. \& Zhang, X. (2017). Investigation and analysis of knowledge, attitude, self-efficacy and behavior intention of cardiopulmonary resuscitation in senior high school students. China Medical Engineering, 25(01),

11-15 https://kns.cnki.net/kcms/detail/detail.aspx?FileNam $\mathrm{e}=$ YCGC201701004\&DbName $=$ CJFQ2017

Zhao, J., Ju, D., Huang, L., Lei, X., \& Tan, L. M. (2013). An investigation into the recognition of cardiopulmonary resuscitation of students in a university. Zhonghua Wei Zhong Bing Ji Jiu Yi Xue, 25(2),

$121-122$ https://pubmed.ncbi.nlm.nih.gov/23648168/

Zhou, G., Lu, G., Shi, O., Li, X., Wang, Z., Wang, Y., \& Luo, Q. (2019). Willingness and obstacles of healthcare professionals to perform bystander cardiopulmonary resuscitation in China. International Emergency Nursing, 47, 100788. https://www.sciencedirect.com/science/article/abs/pi i/S1755599X19300746
Abbreviations
CPR: Cardiopulmonary Resuscitation
OHCA: Out-of-Hospital Cardiac Arrest
EMS: Emergency Medical Services
TPB: The Theory of Planned Behavior
SN: $\quad$ Subjective Norm
AB: Attitude towards the Behavior
PBC: Perceived Behavioral Control 